\title{
Preliminary Study for the Artist Francis Bacon in the Perspective of the Unconscious
}

\author{
Hyun Kwon Lee \\ Lee Hyun Kwon Psychoanalytic Office, Seoul, Korea
}

무의식적 관점에서 본 화가 프랜시스 베이컨에 대한 예비적 연구

이 현 권

이현권 정신분석연구소

This preliminary study aimed at informing the beginning of the following series of theses. Francis Bacon is a painter representing not only Britain, but also the history of art in the 20th century. Thus, many books explain about his works, however, his 'abstruse fear' and his position in the history of art style have not been sufficiently explained. This preliminary study argued that the unconsciousness we experience all the time in clinical practices could explain about the painter's unidentified parts to a certain degree. Also, through analysis on the painter, this study examined the possibilities to explain the perspectives of the unconsciousness through the history of art styles. This study briefly discussed how his superego could transform and how it was connected to his life by looking over a few of his artworks. Through such a process, this study concluded that the perspective of the unconsciousness takes a very important position in understanding Bacon's works. This preliminary study informing the beginning of the analysis on many of other painters, and it will identify how the unconsciousness could be expressed in the paintings under the influences of the era.

Psychoanalysis 2019;30(2):32-39

KEY WORDS: Artist Francis Bacon · The unconscious · Art.

Received: February 19, 2019 Revised: March 31, 2019 Accepted: April 1, 2019

Address for correspondence: Hyun Kwon Lee, MD

Lee Hyun Kwon Psychoanalytic Office, 27 Guuigangbyeon-ro, Gwangjin-gu, Seoul 05115, Korea

Tel: +82-2-2138-7588, Fax: +82-2-2138-7589, E-mail: treeself@hanmail.net

\section{서 론}

이 예비 논문은 영국 출신의 세계적인 화가 프랜시스 베 이컨(Francis Bacon, 1909 1992)에 대한 긴 연구의 출발이 다. 아직 마치지 못한 연구에 대한 짧은 보고이기 때문에 선 명한 길과 결론을 여기서 제시하지는 못할 것이다. 따라서 이 작은 예비 논문은 앞으로 이 작가에 대한 분석을 시작함 에 있어 다소 불친절한 가이드라인 역할을 해줄 수밖에 없다 는 것을 미리 말씀드린다. 하지만 저자가 지금까지 연구한 작가 작업의 대략적인 길들을 조망함으로써, 우리가 임상에 서 매일 경험하고 적용하는 무의식의 경험이 동시대 예술 세 계에 얼마나 중요한 위치를 차지하는지 이해하게 될 것이다.

This is an Open Access article distributed under the terms of the Creative Commons Attribution Non-Commercial License (https://creativecommons.org/licenses/by-nc/4.0) which permits unrestricted non-commercial use, distribution, and reproduction in any medium, provided the original work is properly cited.
화가 프랜시스 베이컨은 20세기 가장 위대한 화가 중 한 명이다. 생전에 세계적인 미술관에서 회고전을 하였고, 그의 작업은 경제적으로나 미학적으로 모두 큰 인정을 받았다. 또 한 앞으로의 예술적 가치는 미술사에서 의미 있는 위치를 차 지할 것으로 예상된다(Sylvester 2015; Hammer 2013). 하지 만 그의 작업은 결코 친절하지 않다. 그는 인간의 비극을 가 감 없이 표현하였고, 공포와 기이함, 난해함은 그의 작업을 대표하는 단어다. 이해할 수 없는 공포가 느껴지는 형체들과 자기나 대상들의 심한 왜곡, 그러한 이미지를 직접 보았을 때 신경을 거슬리게 하는 놀라움, 그리고 시간이 지나도 잊 히지 않는 이미지의 각인은 그의 작업이 주는 전반적이고 독 특한 감정적 경험이다.

그의 이러한 어둡고 공포스런 작업을 그의 발달과 연관시 키는 것은 어렵지 않다. 그는 헌신적인 유모에 의해 길러졌 으나, 말 조련사였던 그의 아버지는 폭군과 같았으며 어머니 는 어린 프랜시스 베이컨에게 감정적인 지지를 제공하지 못 
했다. 아버지에 대하여 그는 “실패한 말 조련사" "정말로 나 쁜 자식(absolute bastard)" 등으로 여긴 반면 자신이 동성애 자임을 깨달은 후 아버지에 대한 강한 성적인 느낌을 자각하 게 되었다(Farson 1983). 또한 그는 어린 시절부터 성인까지 세계 1,2 차 대전을 피부로 생생히 느꼈던 고통스러웠던 세 대이기도 하다. 그는 히틀러에 대하여 분노하였고 관련된 사 진들을 이미지에 차용하였다. 도박이나 알코올 중독과 같은 혼란스런 삶을 살았으며 동성과 이성 모두의 대상에 집착하 였고, 그의 삶은 이런 중요한 대상으로부터 직접적으로 영향 을 받았다(Hammer 2013).

이 지점에서 무의식과 예술의 연관성에 대한 프로이트의 유산을 소개한다(Freud 1910). 프로이트는 르네상스의 천재 레오나르드 다빈치가 그렸던 '두 명의 성녀와 아기 예수'를 분석하면서 그가 보고했던 유일한 기억인 "독수리가 꼬리로 그의 입을 쳐서 벌렸다"는 내용을 중심으로 그의 어머니를 향한 사랑의 소망을 이루었다고 주장하였다. 이 작업은 실제 로 프로이트의 천재성으로 분석되었다. 기존 자료들의 세밀 한 분석을 통해 마치 그의 저서〈꿈의 분석〉에서, 발현몽에 서 잠재몽을 찾아내듯 이미지에서 숨겨진 무의식의 길을 찾 아내었다.

하지만 저자는 이런 질문을 하게 되었다. "레오나르도의 다른 그림에서 무의식은 어떻게 표현되었는가?” "그 시대 및 이후 다른 작가들의 그림들은 이를 어떻게 표현하였는가?” 이러한 질문들의 꼬리는 “그럼 이 현대 예술가들이 마음껏 표 현하는-프랜시스 베이컨처럼-무의식적 내용들은 어떤 과정 을 통해 이루어졌을까?”로 이어졌다. 기본적이나 중요한 위 질문에 대한 통찰은 아마도 무의식에 대한 관점을 토대로 미 술사에 대하여 공시적 이해와 통시적 줄기를 만들어내야 하 는 어려운 과정을 거쳐야 할 듯하다.

지금 이 시점에서 할 수 있는 것은 지금의 주제인 프랜시스 베이컨에 대한 무의식적 분석이 위 질문에 대하여 어느 정도 단서를 제공해 줄 것이라는 점뿐이다. 사실 그 단서의 제공 역시 난해한 작업임이 분명하다. 또한 이 제한된 예비 논문에 서 이러한 복잡한 길에 약간이나마 질서를 만들어야 된다는 어려움이 있다.

무의식의 관점에서 새로 쓰게 되는 예술의 양식사를 위해 저자는 2018년 춘계 한국 정신분석 학회에서 "The unconscious and the artistic world-Focusing on before and after Avant-garde'라는 주제로 발표할 때, 바로크 작가들의 감정 이 현대 작가들의 무의식으로 이어지는 대략의 흐름을 다루 었다. 양식사의 급속한 변형과 해체의 페달을 밟게 된 시기 가 1890년대 중반부터 1990년대 중반까지 이어져온 서구 유 럽의 아방가르드 운동(Avant-garde movement)으로 보았
고, 그 시기의 많은 대표적인 작가들의 예술 작업을 통해 그 변화의 흐름을 간단하게 추적하였다. 결론은 시각 예술 양식 의 해체와 변형은 그 시기 작가들의 내면 구조의 변형과 해 체의 결과이며, 이는 서로 상응하며 발전하였다는 것이다. 저자는 이렇게 이루어진 억압의 해체 결과로 현재의 예술가 들이 개별적 무의식의 내용과 서사를 비교적 자유롭게 표현 할 수 있다고 주장하였다. 이 주장을 토대로 그 다음 과정의 가설을 세워보았다. 그것은 임상에서 경험하는 무의식의 교 류(unconscious communication)(Sandler 1976)가 동시대 작 가들의 작업에서 표현될 수 있으며, 그 결과물이 임상적인 경험과 유사하게 관람자에게 전달될 수 있다는 것이다.

현재의 자극과 과거의 쌓여진 기억, 미래의 틀은 프로이트 의 구조이론에서 중요한 역할을 한다. 대부분의 작가가 그러 듯 작가만의 변하지 않는 양식의 흐름은 견고한 성격 구조 와 상응한다. 또한 작가들의 삶에서 보이는 양식 변화는 '현 재의 시간'과 반응하는 인간 내면의 모습을 반영한다. 이렇 게 예술 분석에 시간성을 고려한다면 개별적 작품 하나하나 에 작가의 현재 경험이 중요한 요소로 작용하게 되며, 이는 그때 상황에 대한 깊이 있는 인터뷰가 필요할 것이다. 실제 인터뷰를 할 수 있다면 더할 나위 없이 좋겠지만 현실적인 이유로 인해 주변의 자료를 사용해야 한다. 한 가지 다행인 것은 이미 유명해진 작가라 인터뷰나 전기 포함, 넘쳐 나는 그와 관련된 서적들이 있다는 것이다.

\section{본 론}

지금까지 말한 여러 제한된 여건 속에서 앞으로 결과물에 대한 몇 가지 정리된 사항들을 말할 수밖에 없음을 미리 밝 힌다. 편의상 몇 가지 작은 소분류를 하여 설명할 것이다. 우 선 베이컨의 회화에서 보이는 그의 개별적 양식의 흐름을 미 술사적 관점에서 간략히 설명할 것이며(개별적인 양식), 다 음에는 그의 개별적 이야기가 이미지에 미친 영향(개별적인 서사), 또한 위의 내용들이 작가의 캔버스에 작가만의 개별 적 공간과 대상으로 어떻게 표현되었는지 알아볼 것이다(개 별적인 공간과 대상). 그리고 이러한 논의는 앞서 언급했던 무의식적 관점의 틀을 견지할 것이다.

\section{개별적인 양식[Individual styles (color, form)]}

모든 화가는 시대의 영향을 피할 수 없다. 예를 들면 시대 를 넘어서는 천재라 불렸던 레오나르드 다빈치 역시 스푸마 토(sfuato) 기법을 개발하고 원근법을 완성하였지만 그가 속 한 시대적 양식에 제한받을 수밖에 없었다. 근대 이전의 화 가들은 대부분 시대적으로 결정된 양식의 틀 내에서 그려야 
했고, 그 양식의 해체는 근대 유럽의 아방가르드 운동의 결과 였다. 베이컨은 선배 화가들의 업적에 힘입어 자신의 감정과 세계를 자신의 개별적 양식으로 표현할 수 있었다. 그는 무의 식적으로 지배했었던 획일화된 양식의 시대가 아닌 스스로 필요한 양식들을 선택해 사용할 수 있는 시대의 화가였다.

베이컨의 선과 색의 흐름은 지극히 개인적이다. 근대 이후 대가들의 감정과 관념은 붓의 개별적 움직임으로 표현된다. 이 당연해 보이는 이야기는 근대 이전에는 전혀 당연하지 않았다. 그 역사적 흐름을 모두 기술할 수는 없지만, 결과적 으로 감정의 선을 붓과 일치시킨 화가는 바로 고흐의 작업 들이며, 그 흐름은 후대 프랑스의 야수파, 오스트리아나 독 일의 표현주의 등으로 발전된다. 따라서 베이컨이 고흐의 작 업을 자신의 방식대로 재해석한 시도(Study for Portrait of Van Gogh III, 1957)는 살펴볼 필요가 있다(Figure 1). 그는 고흐를 동일시했지만, 베이컨의 시대는 고흐의 감정 이상무의식적 감정-을 표현할 수 있는 시대였다. 대지와 산은 바 로 그 자리에서 베이컨이 느끼는 격정적이고 원시적인 감정 의 색을 띤다. 무질서하고 선명한 붉은 선들은 그가 밟고 있 는 땅이 비극의 땅임을 나타내고, 노랑과 빨강색, 짙은 녹색 으로 단순화된 배경은 자신의 공간이 원초적인 세계임을 나 타낸다. 베이컨의 모습과 동일시하여 그려진 고흐의 모습은 어두운 붓의 흐름으로 자신의 혼란스러운 실존의 모습을 드 러낸다. 이것은 베이컨이 고흐의 삶과 붓을 차용하여 베이컨 내면의 것으로 고흐의 그림을 변용시킨 대표적인 예이다.

그의 감정적인 붓의 흐름을 고흐로부터 받았다면 베이컨 회화의 특징인 공간과 대상의 자의적 변형과 왜곡은 어디에 서 왔을까? 사실 이 질문은 앞서 고흐의 업적과 같이 서양 미 술사에서 이론적 합의가 되었다. 현대 예술의 시작을 알린 피카소의〈아비뇽의 아가씨들〉은 큐비즘을 세상에 알림과 동시에 르네상스 시절부터 유지되었던 공간과 대상의 완전 한 해체를 가져왔다(Foster 등 2012). 베이컨 그림의 대상과 공간은 이러한 큐비즘의 업적에 깊게 영향을 받았다.

정규 미술 교육을 받지 않았던 베이컨은 자신의 예술을 시 작하기 전에 피카소의 작품에 깊은 인상을 받았다(Wieland 2010). 이는 마치 그가 고흐의 감정의 붓을 동일시했듯이 피 카소의 작업을 차용하여 자신의 것으로 만들 가능성을 의미 한다. 이러한 영향으로 베이컨의 공간은 자의적으로 세팅되 고, 자화상을 비롯하여 대상은 심한 왜곡과 변형을 보인다. 어떤 경우에는 그 형체를 알아보지 못할 정도로 액체같이 그 대상이 흐늘거린다. 주목해야할 사실은 베이컨은 자신의 이 런 난해한 작업의 결과물을 더 ‘사실적'이라고 믿었다는 것이 다(Sylvester 2015).

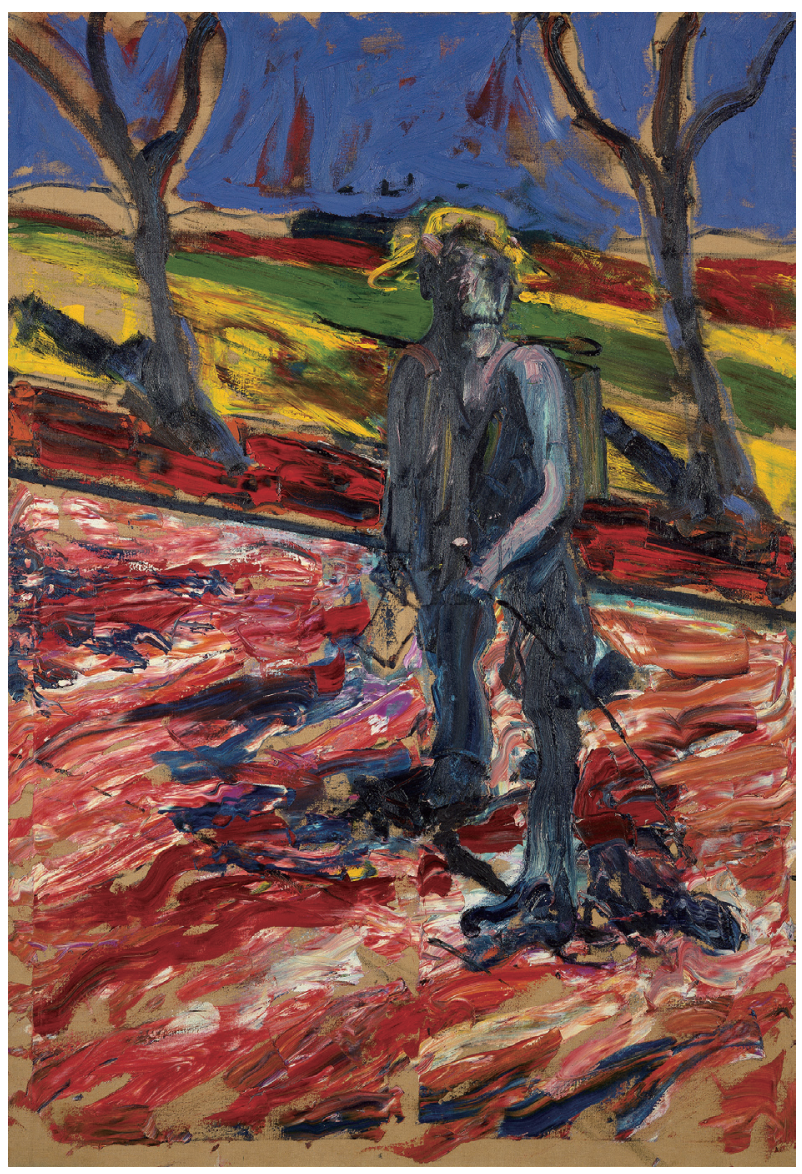

Figure 1. Francis Bacon (1909 1992), Study for Portrait of Van Gogh III, 1957, 198×142 cm. Hirshhorn Museum and Sculpture Garden, Smithsonian Institute, Washington, DC. Reprinted by permission of Hirshhorn Museum and Sculpture Garden.

\section{개별적인 서사(Individual narratives)}

미술 양식사에서 인간의 개별적 감정과 작가 자신의 양식 과의 결합은 해체와 변형의 결과물이었다. 이와 마찬가지로 개별자의 이야기가 의식의 캔버스에 온전히 담기기까지는 긴 역사적 과정을 거쳐야 했다. 프로이트가 분석했던 레오나 르도의 무의식적 환상은 당시 회화의 양식과 그 시대의 이야 기에 숨겨져 있었다. 당시 개인의 이야기를 대체해왔던 신화 나 성경은 시대의 점진적인 변화에 따라 약해지고 개인의 이 야기가 나타나게 된다. 그리고 언제부터인가 임상에서 경험 하는 무의식 이야기, 즉 무의식적 환상(unconscious fantasy) 이 거리낌 없이 이미지에 등장하게 된다.

따라서 베이컨의 회화를 보고 무의식적 환상을 추측하는 것은 다빈치의 그림보다 훨씬 수월할 수 있다. 하지만 저자 는 그의 발달 과정을 분석하여 정신 역동을 분석하려는 것이 아니다. 일부는 그런 면이 들어간다 해도, 가장 중점을 두는 것은 예술을 보는 관점에서 무의식이 중요한 요소라는 것과 예술적 체험이 단순한 욕망의 표현이 아니라 구조의 표현이 
며 역사적으로 큰 변화의 맥락 안에 있다는 것이다.

베이컨은 많은 작품들을 남겼다. 분석 상황에서 환자들이 매일같이 다양한 꿈과 백일몽을 통한 자신의 무의식적 환상 을 보고하며, 그 하나의 이야기에도 중첩된 의미가 있다. 복 잡하고 다층적인 무의식의 이야기들이 그의 많은 회화 속에 담겨있다면, 어떻게 그의 회화와 무의식적 환상을 연결할 수 있을까?

지금 연결시킬 수 있는 것은 베이컨이 1920년대 회화를 본 격적으로 시작하기 전에 크게 감명을 받았던 푸생(Nicolas Poussin, 1594 1665)의 그림 'Massacre of the Innocents (1625)'이다(Hammer 2013)(Figure 2). 어느 건장한 군인이 아이의 어머니 만류에도 아이를 향하여 긴 칼을 들고 한 발 로는 아이의 가슴과 목을 누르는 극적인 장면이다. 사실 이 러한 장면의 인상은 그의 이후 작업에서 영향을 준다. 이는 초자아에 대한 무의식적 환상처럼 가정되며, 다양한 형태로 변화하면서 표현된다.

\section{개별적인 대상과 공간(Individual object, space)}

베이컨의 초기작은 대상과 공간이 분리되지 않았다(Figure Study I, 1945-1946)(Figure 3). 베이컨의 회화가 단순한 관찰 의 표현이 아니라 내면을 통과한 배경과 공간이라면, 이 분 리되지 않는 공간과 대상은 베이컨이 인지(perception)한 결 과물일 것이다. 이는 마치 원시인들이 대상의 속성과 공간을 구별하지 못하고 이해했던 신화 이전의 시기, 또는 공간과 대상을 어떤 시대적 논리로 연결시켜 이야기로 배치했던 신 화의 시기와 유사하다. 이 경험은 유아 발달기와 비슷하며 이를 퇴행의 결과물로 해석하기보다는 자아의 허락하의 퇴 행(regression in the service of ego)으로 이해하는 것이 옳

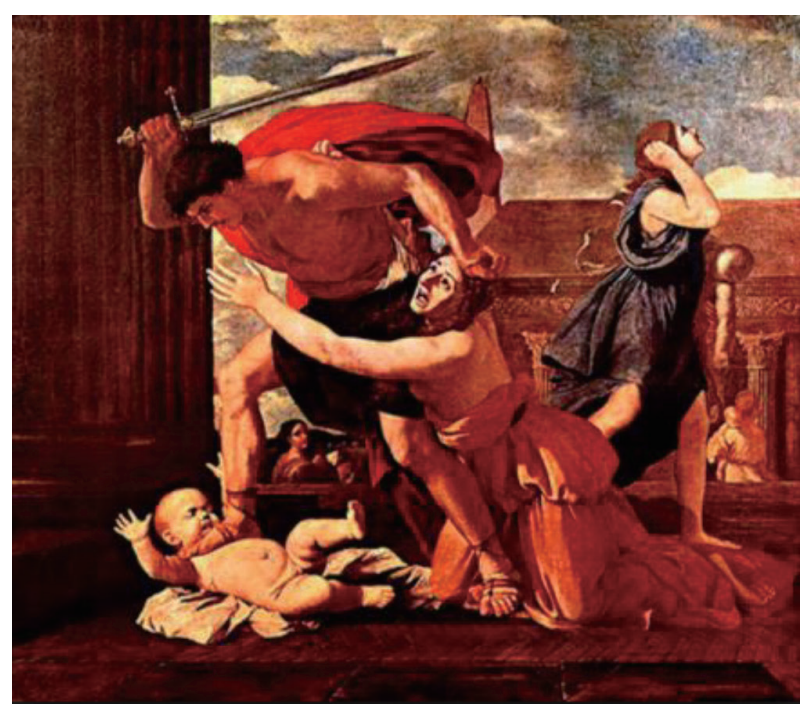

Figure 2. Nicolas Poussin (1594-1665), Massacre of the Innocents, $1625,147 \times 171 \mathrm{~cm}$. Musee Conde, Chantilly.
다(Kris 1936).

그의 무의식적 환상이 푸생의 그림과 깊은 연관이 있고, 그 가 이미지를 통해 퇴행할 수 있는 힘이 있다면, 이제 그의 환 상이 어떤 파생체(derivatives)로 나타나는지 그의 예술에서 살펴보아야 한다. 여기서 베이컨의 대표작이며 많은 평론가 나 저자들이 언급했던 '십자가 형벌(Crucifixion)' 시리즈가 중 요하다. 주제는 베이컨에게 초기부터 후기까지 이어지는 관심 의 대상이었으며, 무의식의 관점에서 이 주제는 그의 평생 작 업에서 정도의 차이가 있지만 다양한 형태로 변주가 되었다.

아버지에 의한 아들의 살해, 죄 사함, 죄책감 등의 다양한 상징을 포함한 '십자가 형벌'의 주제는 초기 기독교 역사부터 현재까지 이어진다. 유사한 주제이지만 그 의미는 시대에 따 라 변화한다. 근대 이후에는 시대적 서사의 힘은 약해지고, 개인의 내면세계에서의 십자가 형벌이 중요하게 된다. 베이 컨에게 있어 '십자가 형벌' 시리즈는 그의 아버지로 상징되는 초자아와 관계되어 있다. 그의 부모는 베이컨을 이해하지 못 했고, 아버지는 군주적이었고, 베이컨은 유모에게 더 애착을 느꼈으며, 동성애적 성향과 성인기에 아버지에 대한 강한 성 적 감정을 고백하였다. 이를 참고로 하여 유사한 시기에 그린 두 작품(Three Studies for Figures at the Base of a Crucifixion, 1944; Painting, 1946)을 중심으로 분석하고자 한다(Figure 4, 5).

베이컨은 인지(perception)된 것을 무의식 이야기로 전환 하여 이를 삼면화 또는 하나의 이미지로 표현하였다. 삼면화

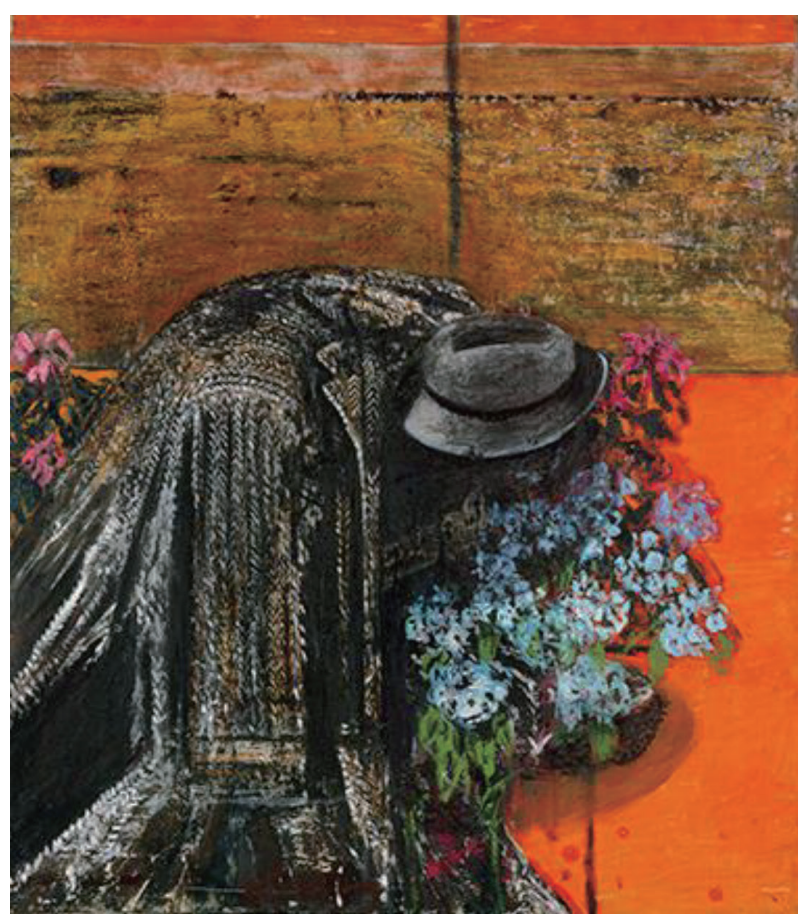

Figure 3. Francis Bacon (1909 1992), Figure Study I, 1945-1946, $123 \times 105.5 \mathrm{~cm}$. National Galleries of Scotland, Edinburgh. 

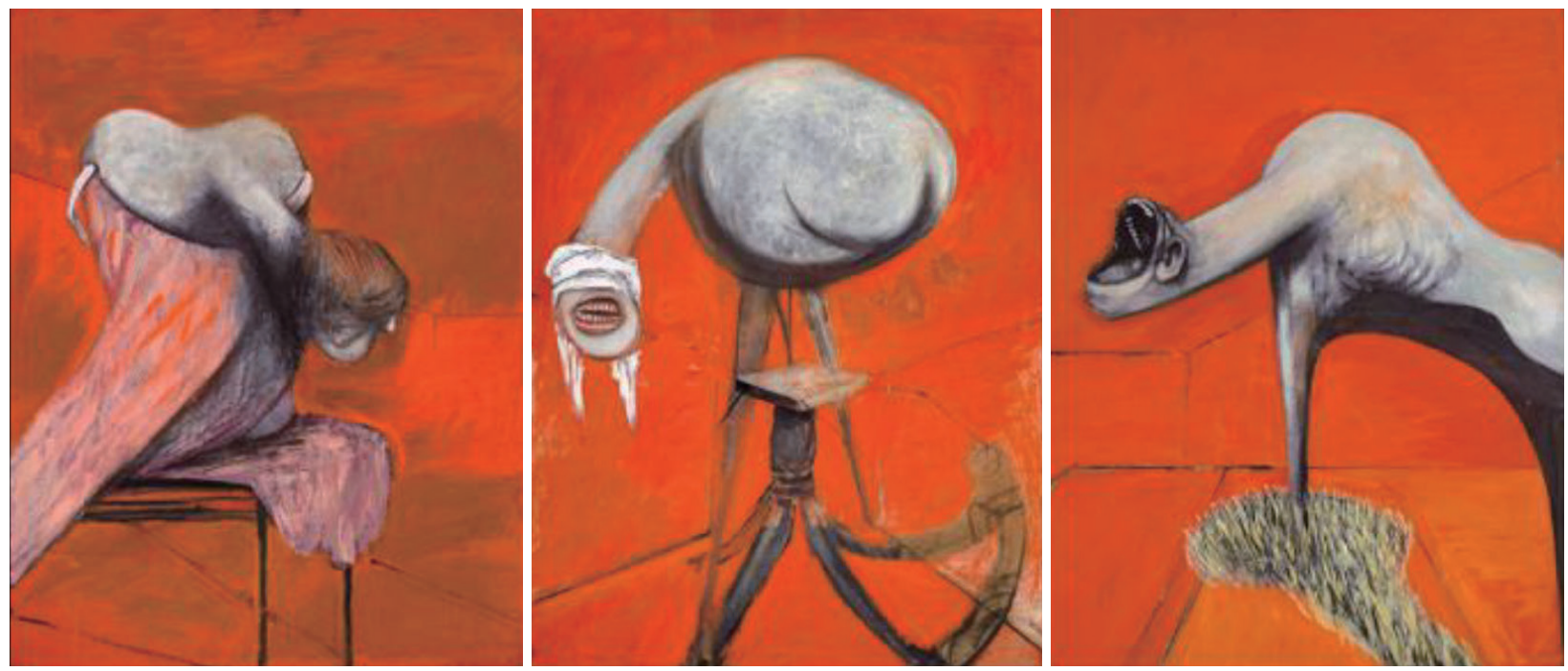

Figure 4. Francis Bacon (1909 1992), Three Studies for Figures at the Base of a Crucifixion, 1944, Triptych, each panel: $94 \times 73.7 \mathrm{~cm}$. Tate, London.

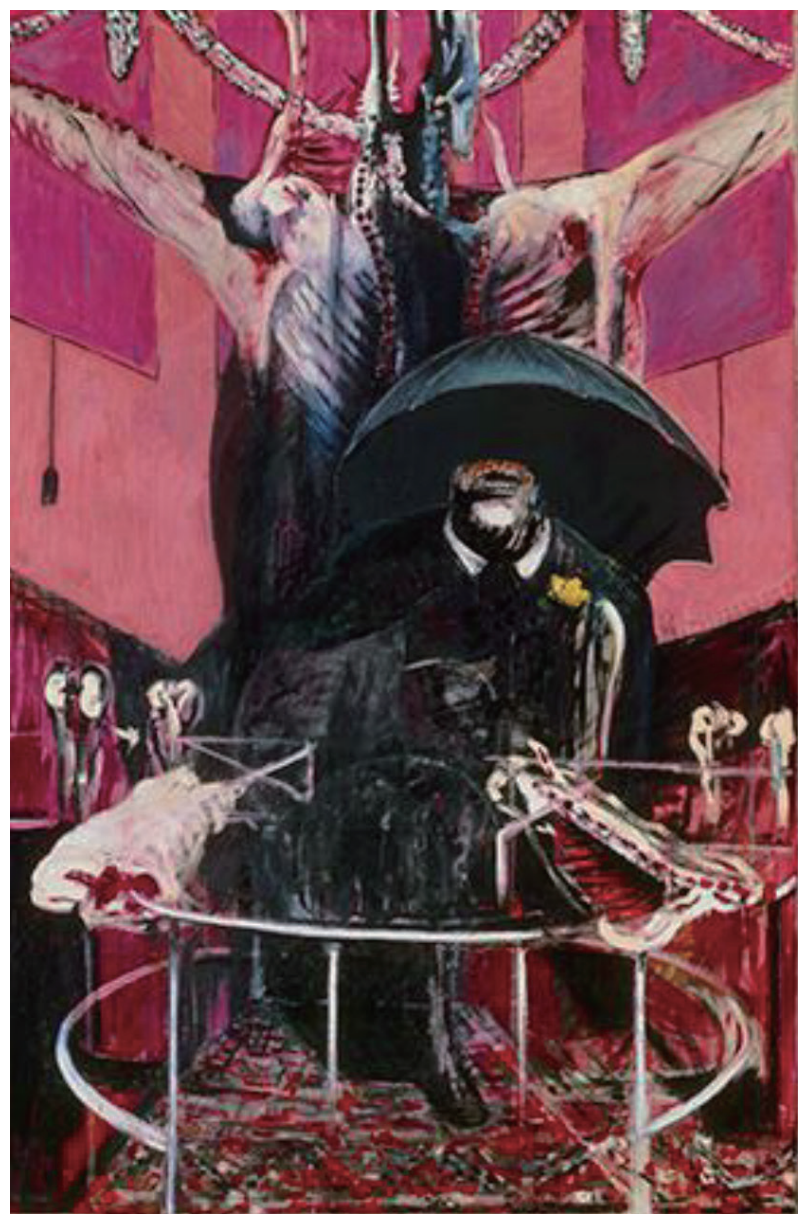

Figure 5. Francis Bacon (1909 1992), Painting, 1946, 198×132cm. The Museum of Modern Art, New York, NY.

의 형식은 중세부터 성경 이야기를 효과적으로 표현하기 위 한 방법이었지만, 베이컨은 이를 자신 내면의 이야기를 표현 하기 위한 도구로 사용하였다. 유사한 시기에 그려진 두 그
림들은 서로 상보적으로 저자의 가설의 근거가 된다. 그 가 설은 '삼면화는 베이컨의 초자아에 각각 연결되어 있는 분리 된 대상들을 그린 것이다'이다(Figure 4). 새와 인간을 합친 듯 모호한 대상들이 세 면으로 세팅된 공간에 비극적으로 배치되어 있다. 가운데 형체는 눈을 가리고 고통스럽게 울고 있다. 마치 어떤 피할 수 없는 처벌을 받아야하는 운명을 지 닌 듯 무기력하다. 왼쪽의 그림은 공포 속에서 바라볼 수밖 에 없는 깊은 슬픔이 있다. 시각적으로 보았을 때 그는 가운 데 형벌을 받고 있는 형체에 대하여 어쩌지 못하는 안타까 운 모습이다. 오른쪽은 이 비극을 향해 소리를 지른다. 절규 를 한다. 그 위치가 명령을 내리는 것인지 저항하는 것인지 는 아직 모호하다. 소설 속 등장 인물들은 작가가 내재화한 대상들의 이야기임을 기억할 때, 이 각각의 삼면화는 베이컨 내면 깊게 존재했던 대상들의 구체화된 표현이다.

초자아는 발달과 문명의 산물이며(Freud 1927), 다층적이 며 균일한 형태로 존재하지 않는다(Brenner 1982). 또한 구 별된 심리 장치가 아니라 대부분 자아와 결합되어 있고 특 별한 경우에 그 분리가 경험된다(Freud 1926). 당시, 베이컨 은 초자아의 처벌과 이에 따른 고통에 지배받았다. Three Studies for Figures at the Base of a Crucifixion(1944)의 세 형체는 그 초자아의 지배와 관련되어 있다. 하지만 단순히 아버지의 실제적 처벌의 영향으로만 생각할 수 없다. 정신분 석에서 초자아는 실제 부모가 아니라 내면 안에 환상으로 존 재하는 부모이다.

베이컨의 작업에서 살(flesh)은 중요한 위치를 차지한다. 인간 육체의 변형과 왜곡은 정육점의 고기를 연상시킨다. 정 신분석은 인간의 피부 경험이 어떻게 발달에 영향을 주는지 알고 있다(Bowlby 1958). 베이컨에 있어서 변형되고 해체된 
인간의 육체는 축적된 원초적 기억의 산물이다. 특히 시기에 따라 원초적 공격성과 리비도는 그의 육체에 그대로 표현된 다(Figure 4). 그림에서 보이는 형체들의 표피는 하얀색이다. 피, 즉 생명이 없이 창백하고, 십자가의 형벌, 잔인한 힘 아 래 죽어 있는 것이다. 생명이 없는 상태는 리비도가 없어진 상태. 또는 원초적 초자아가 인간을 지배하는 상태로 이해된 다. 임상에서 이러한 상태에 대해 환자들은 "내가 살아있지 만 죽어 있는 것 같아요", "내 손이 있지만 내 손이 아닌 것 같 아요”로 기술한다. 죽음과 같은 상태, 군주적인 초자아의 공 포, 그 공기가 지배하는 세계이다.

그렇다면 초자아로 대표되는 그 강력한 힘과 영향은 그림 어디에서 표현이 되었을까? 나의 가설은 '이 삼면화에서 초 자아의 존재는 대상화되지 않고 배경, 즉 공간으로 표현되었 다'이다. 무의식적 관점에서 공간은 절대 중립적이지 않다. 공간은 대상들의 무의식적 경험에 따라 변화한다. 오히려 중 립적 공간에 대한 규정은 이성이 인위적으로 만든 뼈대 같 은 세계이다. 나는 이 삼면화 배경 자체가 초자아의 힘, 영향 으로 채워진 공간이며, 이 힘에 의해 눌려 있던 세 형체들이 분리되어 표현된 것이라고 주장한다. 짐작하다시피 이 공간 과 형체들은 당시 베이컨 내면의 잔인한 무의식적 공간과 대상이며 그는 이런 방식으로 자신의 무의식을 표현하였다.

흥미롭게도 이 보이지 않는 힘-초자아-은 시간이 지나면 서 구체적 형태를 지니게 된다. 이는 앞의 삼면화를 그린 이 후 바로 그린 그림에서 어떤 괴물의 형체로 나타난다(Painting, 1946)(Figure 5). 이 괴물 같은 모습은 인간의 형체지만 여전 히 난해하다. 흥측하게 벌린 입만 보이는 얼굴과 사제 같은 검 은 옷이 그 존재감을 드러낸다. 정육점의 고기가 인물 뒤에는 십자가의 형태, 앞에는 두 가지로 나뉘어 나열되었다. 특징적 인 것이 얼굴의 반을 덮고 있는 우산과 앞의 고기를 지지해주 는 듯한 선들이다. 배경은 짙은 핑크가 지배적이고 바닥의 카 펫도 붉음과 검정 무늬가 있지만 핑크의 흐름과 유사하다.

Three Studies for Figures at the Base of a Crucifixion (1944)의 배경색인 오렌지 빛깔이 초자아 대상을 품은 공간이 라면(Figure 4), 초자아 대상을 구체화한 'Painting(1946)'의 배경색인 핑크는 분리된 초자아를 위한 공간을 만든다 (Figure 5), 공교롭게도 베이컨은 이 시기에 히틀러와 이와 연관된 사진들을 모았었고, 이 핑크의 배경은 한 건축가가 히틀러를 위해 만든 공간의 색이다(Hammer 2013). 이렇게 이 괴물 형상이 베이컨의 초자아로 구체화되었다는 것을 이 해한다면, 베이컨을 설명하는 여러 관점과는 다른 정신분석 적으로 다음과 같이 해석할 수 있다. 아버지의 영향을 받지 만 실제 아버지가 아니라는 것, 그리고 발달 시기에 두 번의 큰 전쟁이 어떤 자극 요소는 되었지만 직접적인 이유가 아
니라는 것이다. 그리고 내재화된 이 초자아 대상을 그린 베 이컨의 그림은 마치 꿈의 영상과 이야기처럼 초자아와 관련 된 무의식적 환상을 담고 있다는 것이다.

이 초자아 파생체는 또 다른 형태로 변화가 된다(Study after Velazquez's Portrait of Pope Innocent X, 1953)(Figure 6). 흥미롭게도 이 교황 그림 시리즈는 'Painting(1946)(Figure $5)^{\prime}$ 을 완성하고 바로 시작하였다고 하며 이후 20여 년간 계속 되었다고 한다(Hammer 2013). 괴물의 형체는 무소불위의 종교 권력의 아이콘인 교황으로 더 구체화되었다. 이 다양한 시리즈를 추적하는 것도 의미가 있겠지만 지금은 그 시리즈 의 대표작인 Study after Velazques's Portrait of Pope Innocent X(1953)를 통해 무의식의 흐름을 살펴보고자 한다(Figure 6).

무릇 대부분의 작가는 선배 대가들의 작업을 재해석하지 만 베이컨이 그린 벨라스케스의 Pope Innocent X를 바라보 는 시선은 독특하다. 권위를 상징하는 의자는 마치 전기의자 와 같이 그려지며, 교황 역시 그 고문을 받는 듯 고통스럽게 입을 벌리고 있다. 이는 감당할 수 없는 존재의 힘을 무력화 시키는 듯한 장면이다. 그 고문의 고통스런 순간을 베이컨은 이미지에 정지시킨다. 하지만 다른 베이컨의 작업에서 그러

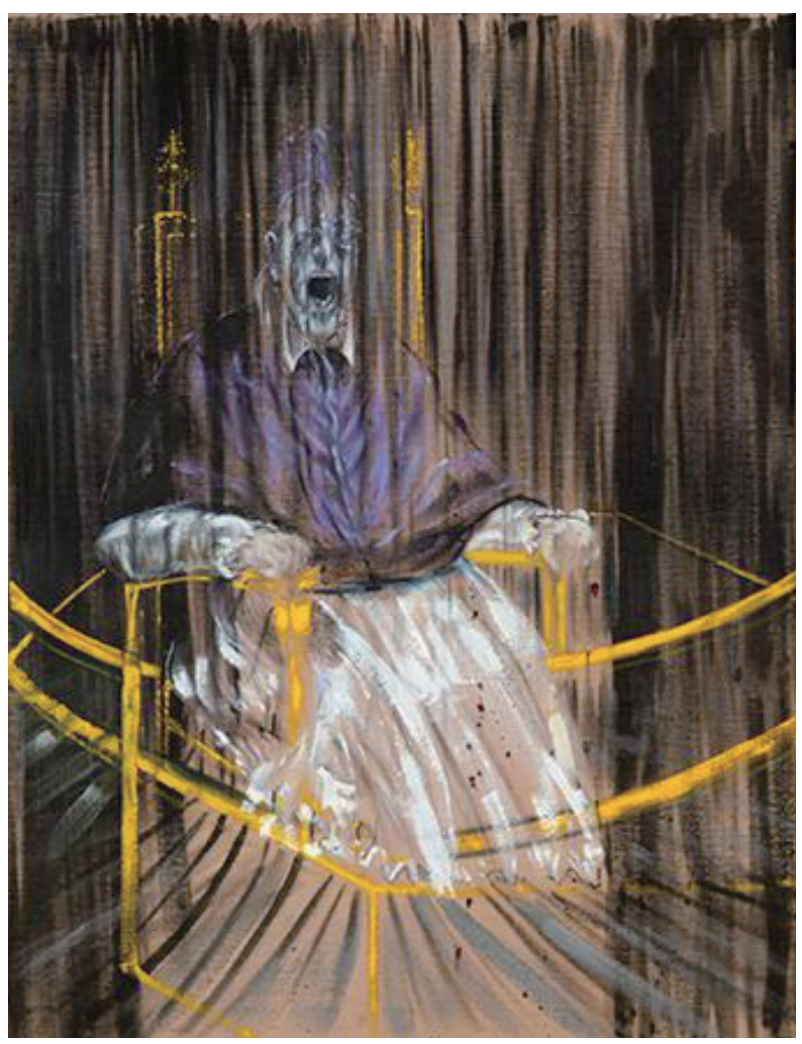

Figure 6. Francis Bacon (1909 1992), Study after Velazques's Portrait of Pope Innocent X, 1953, 153×118 cm. Des Moines Art Center, Des Moines, IA. Reprinted by permission of Des Moines Art Center. 
듯 베이컨의 '정지'는 고정이 아니다. 베이컨은 정지를 시킨 후 더 강력하게 운동을 한다. 그 순환하는 듯한 살아있음 (living)은 그 고통의 순간을 신경의 끝까지 밀고 나가게 하 며, 멈추지 않는 공포의 느낌을 생생하게 전해준다. 그가 긴 시간 시리즈로 보여준 이 무력화와 통제는 인간이 문명 이전 감당할 수 없었던 자연을 신화의 이야기로 통제하는 것과 유 사한 과정이며(Freud 1927), 또한 아이들이 어떠한 틀로 초 자아 대상을 규정하며 대상을 바라보는 것과 흡사하다. 단지 베이컨에게는 이미지와 같은 더 강력한 통제 수단이 필요했 을 뿐이다.

앞의 삼면화에서 보였던 베이컨의 분리 습관은 여기서도 나타난다. 초자아의 화신인 교황도 같은 교황이 아니라는 이 야기다. 나치의 권력에 저항했던 Pope Pius XII의 그림은 Innocent X와 사뭇 다르게 인간의 모습이다(Pope I-Study after 'Pope Innocent X' by Velazquez, 1951). 즉, 그 힘을 약화시 킬 이유가 없다는 것이다. 이렇게 드물게 표현된 온전한 인간 의 얼굴은 이후 베이컨의 작업에서 대상 관계의 일면을 보여 주는 중요한 단서가 된다.

이와 연결된 초자아의 힘이 약화된 후의 삶의 모습이 있 다. 그가 본격적인 동성애를 시작한 시기가 공군 조종사인 Peter Lacy를 만난 1952년이라면(Wieland 2010), 그 시기에 앞서 기술했던 초자아의 구체화와 약화가 어느 정도 영향을 주었다고 추측하는 것은 지나친 무리일까? 즉 베이컨의 동성 애적 리비도의 잠금 장치가 해제되었다는 것이다.

여기서 예술이 주는 힘을 예측할 수 있다. 분석 상황에서 그 강력한 초자아를 분석하고 자아의 힘을 강화하지만 베이 컨은 이 초자아를 이미지로 구체화하여 보여주며 강박적으 로 약화시킨다. 사실 그럴 수밖에 없는 것이 베이컨의 초자 아 콤플렉스들 중에 잔인하고 공포스러운 부분이 있지만 다 른 한편으로는 동성애, 즉 아버지를 향한 강력한 리비도의 흐름이 있기 때문이다. 정신분석적 관점에서 봤을 때 그의 초기 작업들은 마치 자신 안에 막혀진 생명인 리비도 분출을 위한 작업 같다-물론 여기서 자아의 흔적도 그림들에서 표 현된다. 이후 작업들은 이제 비록 왜곡과 변형이 되지만 이 원초적 리비도와 공격성이 좀 더 구체적으로 대상이나 셀프 의 형태로 혼재되어 표현된다.

\section{결 론}

저자는 이 글에서 초자아의 개념이 어떻게 베이컨의 그림 에서 이미지화되고 변화되었는지 간략하게 알아보았다. 그 리고 그 군주적인 초자아가 약화됨으로써 그의 리비도에 어 떻게 영향을 미쳤는지 그의 삶을 통해 추정해 보았다. 이런
작은 근거들은 프로이트의 구조이론을 비롯하여 임상적으 로 쌓아온 정신분석학의 경험들이 이미지 분석에 중요한 위 치를 차지할 것이라는 점을 기대하게 한다. 저자는 이를 이 후 논의하게 될 베이컨의 작업 분석에 틀로 사용할 것이다. 그의 초상화와 자화상, 이어지는 여러 그림들에 대하여 정신 분석의 이론과 경험이 중요함을 밝히게 될 것이다.

베이컨은 죽음과 같은 어둠을 그렸지만, 그는 살기 위해 그릴 수밖에 없었다. 고통의 현재는 그가 선택한 것이 아니 었다. 이제는 많은 이들이 짐작하듯 그의 '마조히즘'은 그의 현재를 과거 기억의 어둡고 공포스러운 안경으로 보게 했으 며, 이는 그의 결정되지 않는 시간, 즉 미래 역시 죽음의 거친 물결에서 벗어날 수 없게 하였다. 하지만 그는 '결정된 듯한' 운명의 기차에 온전히 자신을 맡기지 않았다. 그의 그림에는 이런 치열한 투쟁의 과정이 느껴진다. 피부와 같이 붙은 그의 내면의 괴물-군주적인 초자아-을 평생 벗겨내야 살아나는 생명의 줄기를 위해 그는 그림을 그릴 수밖에 없었다. 따라서 그의 그림은 그의 현재를 중심으로 과거-미래가 연결되어 있 다. 그 시간의 연결성은 그의 그림에 독특한 특성을 부여한 다. 저자가 여기서 말하고 싶은 부분은 이 시간성의 성격이 정신분석과 공유하는 영역이 있다는 것이다.

인간은 집단에서 살아갈 수밖에 없고 집단의 알고리즘은 인간 내면에 의식/무의식 중에 각인이 된다. 그것이 사회 구 조이고 내면화된 것이 인간 성격의 구조라면, 인간과 사회는 그 알 수 없는 보이지 않는/의식되지 않는 선들로 연결되어 있을 것이다. 따라서 그의 이미지는 베이컨의 내면이 투영된 심리적 공간이다. 베이컨은 그의 이미지를 통해 이 미개척의 공간을 화석과 같이 고집스럽게 고정시켰다. 무의식에도 질 서가 있다. 프로이트의 위대한 발견은 이성의 철학이 카오스 로 규정했던 무의식에 일정한 원칙을 제시했던 것이다. 그것 이 구조이든, 대상 관계이든, 어떤 개념 안에 속해 있느냐가 중요한 것이 아니라 일정한 알고리즘의 형식이 의식 아래에 존재한다는 것이다. 저자가 하고 싶은 것은 프로이트가 의식 의 층 아래 그 혼란스럽고 강력한 에너지에 언어를 부여했듯 이, 예술도 역시 그 무의식의 흔적들이 있을 것이고 그 질서 를 발견해 낼 수 있다는 것이다. 현대 철학자 질 들뢰즈가 베 이컨의 작업에 대하여 〈감각의 논리〉라는 책을 저술했지만, 저자는 무의식의 관점에서 그의 작업 안에는 '무의식의 논 리'를 발견할 수 있다고 주장한다.

\section{Conflicts of Interest}

The author has no potential conflicts of interest to disclose.

\section{ORCID}

Hyun Kwon Lee: https://orcid.org/0000-0002-6193-2552 


\section{REFERENCES}

Bowlby J. The nature of the child's tie to his mother. Int J Psychoanal 1958;39:350-373.

Brenner C. The concept of the superego: a reformulation. Psychoanal Q 1982;51:501-525.

Farson D. The gilded gutter life Of Francis Bacon: the authorized biography. New York, NY: Pantheon Books;1983.

Foster H, Krauss R, Bois YA, Buchloh BHD, David J (Trans. Bea SH, Shin JH, O UK, Kim HK, Cho HJ, Kim IK, et al.). Art since 1900: Modernism, Antimodernism, Postmodernism. Seoul: Semicolon;2012. p.78.

Freud S. Leonardo da Vinci: a memory of his childhood. SE 11. London: Hogarth press;1910. p.57-138.
Freud S. Inhibitions, symptoms and anxiety. SE 20. London: Hogarth press;1926. p.75-174

Freud S. The future of an illusion. SE:21. London: Hogarth Press;1927. p.1-56.

Hammer M. Francis Bacon: Phaidon focus. New York, NY; Phaidon Press Inc;2013. p.52-54

Kris E. The psychology of caricature. Int J Psycho-Anal 1936;17:285-303. Sandler J. Dreams, unconscious fantasies and 'identity of perception.' Int $R$ Psycho-Anal 1976;3:33-42.

Sylvester D (Trans. Ju EJ). Interviews with Francis Bacon. Seoul; DesignHouse: 2015.

Wieland AM (Trans. Lee SY). living_art: Francis Bacon. Seoul; Yekyong:2010. 